\title{
Jean Luc-Nancy y Maurice Blanchot: el reparto de lo inconfesable
}

\section{Jean Luc-Nancy and Maurice Blanchot: the sharing of the unconfesable}

\author{
Cristina Rodríguez MARCIEL
}

UNED

crmarciel@invi.uned.es

Recibido: 21/01/2011

Aceptado: 20/06/2011

\section{Resumen}

A partir de una circunstancia personal, la autora de este artículo mantiene con Jean-Luc Nancy un intercambio epistolar a propósito de las "lecturas" que cada uno de ellos ha hecho de La Communauté inavouable de Maurice Blanchot. En su día, el libro de Blanchot apareció como una "respuesta" a La Communauté desæuvrée de Nancy desencadenándose, a partir de ambos textos, lo que desde ese momento fue una insólita forma de abordar la cuestión de la comunidad. ¿Por qué entonces la desconcertante inclusión en el libro de Blanchot de una enigmática segunda parte "dedicada" al libro de Marguerite Duras, La Maladie de la mort? ¿Por qué la inclusión en su libro de un relato acerca de las noches que pasa un hombre, aquejado de la "imposibilidad de amar", con una joven con la que lo único que le vincula es el contrato de unas noches pagadas y en cuyo cuerpo desea encontrar la vida que a él se le escapa? "Arrancándole" al propio Nancy una "respuesta" a esta cuestión y en diálogo con él, la autora de este trabajo emprende su propia búsqueda (que no elucidación) del texto de Blanchot.

Palabras clave: Blanchot, Nancy, Duras, comunidad, muerte, escritura, relación sexual. 


\begin{abstract}
From a personal circumstance, the author of this paper keeps up correspondence with Jean-Luc Nancy about the "readings" that each of them made about Maurice Blanchot's La Communauté inavouable. At that time, Blanchot's book appeared as a "response" to Nancy's La Communauté desœuvrée, being triggered off, from both texts, what, from that moment, was an unusual way to approach the question of the community. So, why the inclusion of an enigmatic second part "dedicated" to the Marguerite Duras's book, La Maladie de la mort, in the Blanchot's book? Why the inclusion in his book of a story about the nights that a man spends, complained about "the impossibility to love", with a young woman with which the only thing, that binds her, is the contract for any paid nights and in which body he wants to find the life that misses him? The author of this work, "extracting" to Nancy himself a "response" to this question and in dialogue with him, undertakes her own research (not elucidate) of Blanchot's text.
\end{abstract}

Keywords: Blanchot, Nancy, Duras, community, death, writing, sexual relation.

...para callarse, hay que hablar.

Pero, ¿con qué clase de palabras?

Maurice Blanchot, La Communauté inavouable

...y cuando se calla, no se calla. Maurice Blanchot, Le Dernier homme

Sin que hubiera sido concebido o planeado de antemano, este texto se ha transformado en una especie de partage des voix que muestra cómo lo compartido no consiste sino en la potencia y en la pasión de comunicarse. Por lo demás, las circunstancias que han concurrido para que este texto pueda llegar hoy al lector en la forma en que lo ofrecemos constituyen una pequeña historia personal que debe ser contada. En diciembre de 2009 defendí en Madrid mi tesis doctoral1 que está dedicada al pensamiento de Jean-Luc Nancy. Nancy, que había sido nombrado Presidente del Tribunal que debía juzgar la tesis, tuvo un problema de salud que requirió unos días de ingreso hospitalario y que, en consecuencia, le impidió viajar a Madrid para asistir al acto de defensa. Dado que el Tribunal había sido ya citado, el acto no pudo posponerse para esperar la recuperación de Nancy quien, finalmen-

\footnotetext{
1 Rodríguez Marciel, C.; Nancyt(r)opías. Topografias de una filosofía por venir en Jean-Luc Nancy, Madrid, Dykinson, 2011.
} 
te y unos días antes del acto, tuvo que ser sustituido. Me faltarán eternamente las palabras con que agradecer el modo en que Nancy, fatigado y aún convaleciente, intentando hacer que los médicos repararan a toda prisa y una vez más la maquinaria de "ese corazón protético" que no es el suyo y que -como él me escribió en esa ocasión- le "señala de cuando en cuando su independencia caprichosa", hizo cuanto pudo por estar conmigo el día de la defensa y para que esa escena tuviera lugar "avec", con él, haciéndome sentir su presencia de partenaire invisible. Todo lo que puedo decir es que, aquel día, él estuvo allí. Puedo afirmar sin temor a equivocarme que, a buen seguro, sea éste el único y muy extraño caso en el que el acto de una defensa de Tesis ha contado con dos presidentes en el Tribunal. Si bien se piensa, ¿pudo acaso ocurrir de otra manera? La forma que tuvo Jean-Luc Nancy de estar con nosotros ese día fue dejándonos el abandono de su presencia ausente. Y así fue como la thesis, la posición, cedió paso al requerimiento, a l'adresse: "suspendido, el indicativo de la tesis no se abandona, el requerimiento ocupa su lugar en el análisis. Pero cierta provocación alocutoria tiene ahí lugar"'2. Y, efectivamente, cuánta provocación hay en la palabra dirigida, en el hecho de dirigir la palabra, en el intimar de su requerimiento, en su solicitud.

Dos días antes del día en que tendría lugar la sesión de defensa, le envié por correo electrónico a Nancy el texto que yo había elaborado para exponerlo con ocasión del acto y que había aprendido par coeur en francés para pronunciarlo en su presencia. El texto había sufrido su propia transformación, su desplazamiento, poniendo en una dirección inédita su propio sentido: pasó de ser el texto premeditado con el que exponer la labor realizada durante cinco años de trabajo (presentación de la metodología empleada, declaración de las conclusiones alcanzadas y demostración de sus aportaciones originales) a convertirse en un improvisado intercambio epistolar donde, de algún modo, se anticipaba el acto que, así, iba a tener dos tiempos, dos escenas y dos escenarios, porque la noche antes del día de la defensa (quizás fue su modo particular de recordarme el modo en que la comunicación diurna "se acompaña con la comunicación nocturna" y se enreda con ella), Nancy me hizo llegar un escrito con los comentarios, observaciones y objeciones que mi "defensa" le había suscitado, expresando con ello su deseo de no renunciar al lugar que le correspondía en el Tribunal de Tesis. Así pues, el Presidente que sustituyó a Nancy recibió la petición de éste solicitando que se leyera su intervención, en el momento en que el nuevo Presidente juzgara más oportuno. De ese modo, Nancy formó parte sin formar parte del Tribunal que juzgó mi tesis y fue también su forma exquisita de manifestarme la generosidad de un afecto que no he hecho nada para merecer. No puedo decir nada - ¿con qué clase de palabras?-que esté a la altura de su calidez humana y de su dadivoso gesto.

\footnotetext{
2 Derrida, J., Le Toucher, Jean-Luc Nancy, París, Galilée, 2000, p. 36.
} 
A buen seguro, el lector se estará ya impacientando preguntándose acerca de la necesidad de comenzar con esta confidencia, con la narración de unos hechos que pertenecen al ámbito de lo puramente anecdótico con que las vidas de cualquiera y de todos nosotros están tejidas. El relato de esta circunstancia personal hubiera debido quedarse en el espacio de lo que la filosofía ha considerado tradicionalmente hors d'œuvre, un fragmento accesorio y superfluo, prescindible, cuando para la obra, para la obra filosófica, lo que debería ser perseguido siempre por su autor consistiría precisamente en saber distinguir lo anecdótico de lo esencial, en saber separar el grano filosófico, la semilla fértil, de la paja, de la caña hueca que ya no es filosófica ni esencial. Pero sabemos desde Nietzsche que toda obra filosófica disimula un diario íntimo y, en ese sentido, cada filósofo sabe también, aunque sea con un saber muy oscuro e incierto, que "la forma de su pensamiento no es distinta de la de su nariz, la de su nacimiento o la de su manera de estar enamorado"3. En cualquier caso, quizás esta confidencia debería haberse quedado ahí, en el terreno de lo puramente autobiográfico o de la correspondencia meramente privada, si no hubiera sido porque con las observaciones de Nancy recibí un regalo que no puedo guardar para mí, una ofrenda que ya no debe quedarse en el ámbito ni de lo anecdótico ni de lo privado. El obsequio requiere ser compartido, porque en aquel escrito en que Nancy respondía a mi tesis, estaba su propia explicación con Maurice Blanchot a propósito de La Communauté inavouable. Todo lo que puedo decir es que "aquella respuesta me embargó", pero me embargó también el hecho de que la respuesta de Nancy era "una resonancia y una réplica, una reserva y, en cierto aspecto, un reproche" 4 :

...sin embargo, diciendo eso me acorralas: ¿por qué, en definitiva, no he respondido todavía clara y directamente a La Comunidad inconfesable? Sé que el estado más desarrollado de algo que pueda aproximarse a esa respuesta se encuentra en el prefacio que ofrecí para la edición española del libro de Blanchot. Sin embargo, apenas puede hablarse de una aproximación: ni siquiera llegué a coger entre las manos, para volver a leerlo, el texto de Blanchot.

¿Por qué? Me fuerzas a responder inmediatamente.

"Me fuerzas". "Diciendo eso me acorralas". A continuación explicaré qué fue lo que dije y que hizo que Nancy, según sus propias palabras, se sintiera acorralado, poussé dans ses retranchements. Pero de golpe y como un mazazo me di cuenta en ese instante de hasta qué punto mi defensa de tesis no había sido tal, que no había consistido sino en una provocación, en esa provocación alocutoria que tiene lugar

\footnotetext{
3 Nancy, J.-L., «Je ne suis jamais devenu philosophe», en Alphant, M. (ed.), La vocation philosophique, París, Bayard, 2004, p. 101.

${ }^{4}$ Nancy, J.-L., La Communauté affrontée, París, Galilée, 2001, p. 38.
} 
cuando la tesis se suspende para dejar que la palabra dirigida, que el envío de la palabra, esa palabra que vale menos por lo que dice que por el hecho de responder a una solicitación, ocupe su lugar en el análisis, en la tesis. Todos los significados del verbo latino prōvoco estaban siendo ahí puestos en juego: llamar afuera, hacer venir, incitar, excitar, desafiar, retar. Retar. Me fuerzas...

En realidad, el texto de Blanchot -quiero referirme a su segunda parte, aunque está enlazada con la primera- me resulta opaco, misterioso en el sentido de la palabra de no esclarecedor. Observo además, por añadidura, que nadie, que yo sepa, en el mundo -en el que, sin embargo, ese texto ha circulado en tantas lenguas con los otros tantos textos a los que remitía-, nadie ha propuesto en realidad simplemente una "lectura" de estas páginas. ¿Por qué? Es decir, por qué ese texto de Blanchot se resiste tanto. No quiero detenerme ahora en este punto, pero ya que me fuerzas a ello...

Me fuerzas a ello. Dos golpes, la percusión, la repercusión. El efecto de lo que se vuelve contra uno mismo. La venganza china de quien clava contra sí mismo el puñal. El gesto repercutido: "de nuevo su admonición: “¡Ten cuidado con lo inconfesable!"'5. Pero, mi querida Cristina, ya que me fuerzas a ello...

El día en que defendí mi tesis, compartí con los miembros del Tribunal algo que venía asediando mi pensamiento desde hacía años y que no se había explicitado en la tesis (aunque en realidad fuera lo que respiraba en ella en cada línea, o bien lo que la hacía respirar), aventurando en aquel preciso momento una tesis suplementaria o adicional, una tesis improvisada y excedente, que consistía en afirmar que la muy esperada respuesta de Nancy a Blanchot a propósito de La Communauté inavouable, desde hacía mucho tiempo, y todavía hoy, diferida por el propio Nancy6, nos había llegado ya y que se encontraba en un libro dedicado a Lacan: $L$ ' "il y a" du rapport sexuel. En mi opinión, con este libro no se estaba produciendo más que un desvío, un clinamen, una ofrenda oblicua, porque respondiendo a Lacan, a partir de una escucha de Lacan ciertamente no analítica, Nancy había respondido sin responder a Blanchot. Y el "il y a", el "hay" de esa relación sexual, podía leerse, sin duda, como la obra inconfesable de una "comunidad desobrada". Ahora bien, qué clase de obra podía ser ésa, una obra más oculta, más opaca y misteriosa que cualquier desobramiento, pero todavía obra, una obra inconfesable en un lugar atópico que, en consecuencia, ya no es ni œuvre ni hors d'œuvre, pero que convulsiona y disloca el orden del discurso dando lugar, precisamente, a la obra. Una obra en

\footnotetext{
5 Ibidem, p. 44.

${ }^{6}$ Más tarde he reflexionado sobre este asunto y, quizás, en realidad, la forma que tuvo Nancy de responder a Blanchot se cifra en estas tres sencillas palabras situadas en el comienzo de La Communauté affronté: "A Maurice Blanchot".

${ }^{7}$ Blanchot, M., L’Espace littéraire, París, Gallimard, 1973, p. 16.
} 
un afuera absoluto, en el afuera del afuera y, por tanto, en lo más íntimo. ¿Qué clase de obra, de obra "íntima", no dejaría de decirse en el silencio de aquellos que podrían, pero no pueden confesar? Siempre se trataba, en última instancia, de esa obra que nos expulsa, que nos aparta, que nos despide, la que hace de nosotros supervivientes, de la obra que hace que estemos muertos desde que ella existe, "haciéndonos presentir la impresión de un extraño desobramiento"7. Una obra muy especial, por tanto, de unión sin comunión, una obra singular de pasión impasible donde lo que tenía lugar como "relación", fuera o no "sexual" (puesto que la relación sexual vale como el paradigma y la juntura de la relación en general), era la inconmensurabilidad y, en consecuencia, lo "sin relación" de lo que estaba en relación, es decir, algo incompartible, algo de lo que ya no hay reparto. Una obra que consistía en afirmar8 lo inconfesable: "una relación tan singular entre los seres que el amor mismo no es necesario en ella" 9 porque, como dice Nancy, "lo que hace el amor, es lo que excede el amor; el amor "mismo", por tanto, esto es, algo distinto infinitamente de cualquier identificación del amor (pasión, ternura, fidelidad, oblación, etc.). Es decir, el "entre" o el "con" de los "sujetos" que nada objetivará".

En consecuencia, y en mi opinión, ese "hay", menos que confrontarse con el "no hay" de la relación sexual lacaniana ${ }^{10}$, me parecía que se dirigía al hay blan-

\footnotetext{
${ }^{8}$ La primera parte de La Communauté inavouable, «La Communauté négative», no deja de ser una potente confirmación de que la "negatividad" no es el reverso dialéctico de ninguna "positividad". No se trata de superar dialécticamente una "negatividad" que convertiría negatividad, amortizándola sin resto, en "positividad" (así es como se "colman" las pérdidas y se arrojan balances "positivos" que transforman pérdidas en ganancias. Por eso cuando Blanchot alude al principio de "insuficiencia" de Bataille lo hace impidiéndose concluirlo a partir de un modelo de suficiencia), se trata de "afirmarla", "afirmar" la negatividad y, sólo así, "ir más lejos". Ésa me parece que es la operación que precisamente Blanchot reconoce y saluda en Nancy y es por lo que Blanchot recurre a la cita completa de Bataille (es significativo que Blanchot ofrezca esa cita dos veces y la coloque en cada una de las dos partes de su communauté inavouable -las dos partes del libro "sin relación" una con otra o en una relación inconmensurable-) al escribir dos veces: "la comunidad negativa: la comunidad de aquellos que no tienen comunidad" (pp. 45 y 83). Ya lo veremos más adelante porque aunque, según Nancy, Blanchot le hacía una crítica diciéndole que su comunidad no era más que "negativa": "Blanchot me solicitaba no detenerme en la negación de la comunidad comunional y pensar más allá de esta negatividad" (Nancy 2001, op. cit. -nota 4-, p. 41), lo que supo reconocer y elogió Blanchot del trabajo de Nancy fue, precisamente, que por "afirmar" una negatividad (la muerte o la desaparición, vamos a verlo enseguida) sin hacer "obra" de ella y sin "positivarla", Nancy había sabido ir más lejos y que, por consiguiente, la suya era una operación radicalmente "afirmativa". Teniendo en cuenta, por lo demás, que no nos está permitido pensar esta operación como forma alguna de tanatofilía. Nada más lejos. Enseguida veremos el modo en que Nancy reivindica que el "non-rapport" no tiene nada de negativo. Sobre ese "tono afirmativo" véase «Communauté et écriture» (p. 25 y ss.) en Blanchot, M., La Communauté inavouable, París, Minuit, 1983.
}

9 Ibidem, p. 58.

10 Una escucha no analítica de Lacan también recorre el texto de Blanchot: “..."yo" y el "otro" no viven en el mismo tiempo, no están nunca juntos (en sincronía), no podrían ser por tanto contemporáneos, sino separados (incluso unidos) por un "no todavía" que va a la par con un "ya no". ¿No fue 
chotiano, a través del cual lo "sin relación" de la relación ya no podía ser considerado como una modalidad de cierto "no hay", sino de cierto no hay nada más que ese hay, en que para Blanchot consiste en la experiencia de la literatura y de la noche (experiencia que, por lo demás, viene dada por la exigencia más reiterada de Blanchot: el pensamiento de la amistad, esto es, "la forma misma de la comunidad desobrada"; y amistad del pensamiento, es decir, "amistad para con la exigencia de escribir que excluye toda amistad", pensamiento que se deja tocar por otro pensamiento para que, de ese modo, escribir no pueda consistir sino en escribir siempre en nombre del otro). Por su parte, con ese "hay", Nancy no hacía sino señalar hacia una lógica de la relación con la que ponía de manifiesto una vez más la necesidad de pensar que lo que no había quedado resuelto en nuestra tradición por parte de la "ontología" aparecía como la obligación, como la exigencia de pensar la "relación", esto es, de pensar el carácter relacional y no sustancial o estático de la ontología. El "ser" mismo acaba así por definirse como "relación" y eso era lo que ponía al descubierto "la relación sexual" cuya fórmula redundante podía ser tratada como un pleonasmo:

No es imposible que, finalmente, debamos descubrir que "la relación sexual " se comporta como "el ser" (comprendido como verbo y acto) con respecto a lo que sería, en consecuencia, para él "el ente" (y que sería, entonces, la pareja entrelazada). O, si ustedes prefieren, lo que aparea a la pareja no es una pareja, sin ser no obstante uno solo. Lo que aparea y, por consiguiente, lo que "es" en sentido transitivo [...], lo que transita el ente, lo que lo atraviesa y lo transporta, que lo arrebata y que se arrebata en él, es decir, lo que lo exalta y que lo excede al mismo tiempo, a la vez; eso no es ni uno ni dos ni nada que se pueda contar. ${ }^{11}$

Lo que ahora podía ser expresado por Nancy como el "hay" de la relación, ya venía poniéndose en juego de una manera radicalmente novedosa e inaudita a partir de La Communauté desœuvrée, cuyo testigo había recogido Blanchot en La Communaute inavouable, y que venía dado por la necesidad de pensar una ontología relacional en términos de diferencias y de movimiento, esto es, de una forma radicalmente distinta de la ontología del ser fusional o comunional donde la relación acababa siempre por ser reducida a un estado o a una sustancia. El ser de la ontología clásica aparecía siempre como aquello que, en principio, era substraído a la relación y la relación, precisamente, no es sino aquello que deshace en su princi-

Lacan quien dijo (cita quizás inexacta): desear es dar lo que no se tiene a alguien que no lo quiere? Lo que no significa que amar se viva en el modo de la espera o de la nostalgia, términos que se reducen demasiado fácilmente a un registro psicológico, mientras que la relación que está aquí en juego no es mundanal, al suponer incluso la desaparición, hasta el hundimiento del mundo" (p. 71). Nancy ofrece otra versión de esa cita: "El amor da lo que no tiene (según Lacan), y el deseo toma lo que lo excede" (Nancy, J.-L., L' "il y a” du rapport sexuel, París, Galilée, 2001, p. 49).

11 Ibidem, p. 12. 
pio un ser absoluto carente de relación: "la lógica de lo absoluto violenta lo absoluto"12 ("solo, el ser se cierra, se adormece y se tranquiliza. O bien está solo, o no se sabe solo más que si no lo está"13), y la relación o la comunidad, que no es (si es que "es") nada del orden de lo ente, tiene lugar entre los entes y, además, tiene lugar de forma paradójica no "siendo". Es decir, que la relación tiene lugar sólo por la diferencia, la distinción o la separación y, por tanto, no siendo, la relación (nuestra comunidad) distingue y separa a los entes. A través de esta lógica de la relación, Nancy se esforzaba en distinguir aquello que hay en cuanto dado, disponible y presente, de aquello que tiene lugar como venida, como la donación misma de lo que no está dado, pero que $h a y^{14}$, para concluir que "lo sexual es el "hay" de la relación"15.

Por lo demás, cuando se dice que hay o que no hay, es preciso saber dónde está el ahí. Si hablamos de una cosa, puede estar aquí o ahí; pero si se trata de lo que no es ninguna cosa ni ningún ente y, por consiguiente, del todo o de la relación con las cosas, el ah $i$ no es ningún lugar, ningún sitio para una unidad cualquiera, sino únicamente la separación del tener-lugar y del juego del entre-lugares. ${ }^{16}$

En su libro, Nancy señala el modo en que la relación sexual vale como conexión de la relación en general. Ahora bien, esa relación en general no consiste en un puente tendido entre dos individuos, que serían los términos de dicha relación, sino en un movimiento, en una movilidad principiante, en el transporte infinito en que se deja llevar toda finitud, un movimiento infinito que tiene lugar en la relación o, mejor dicho, como relación, y que es la inconmensurabilidad o lo incompartible de aquellos que, al entrar en relación, son atravesados por la relación misma. Toda relación es sexuada si no propiamente sexual y, de ese modo, afirma Nancy, no hay ninguna relación sin eros. Pero tampoco hay eros sin ágape, es decir, sin ese "amor imposible" que el judeo-cristianismo cree poder presuponer como naturaleza de Dios y como mandamiento universal. Ese amor que declara lo imposible mismo me parecía ser la respuesta que Nancy estaba dando sin dársela a Blanchot $\mathrm{o}$, mejor dicho, me parecía ser "la inyunción silenciosa" que circulaba entre Nancy y

\footnotetext{
12 Nancy, J.-L., La Communauté desœuvrée, París, Christian Bourgois, 1986 (4ª ed. 2004), p. 18.

13 Blanchot 1983, op. cit. (nota 8), p. 16.

14 Un ejemplo al azar en un texto de Nancy: "Antes de cualquier captación representativa, antes de una conciencia y de su sujeto, antes de la ciencia, de la teología, y de la filosofía, hay eso: el eso del hay, precisamente. Pero el «hay» mismo no es una presencia a la que remitirían nuestros signos, nuestras demostraciones y nuestras mostraciones. No podemos «remitir»a él, ni «restituirlo»: él está siempre, ya, ahí, pero ni en el modo del «ser» (como una sustancia), ni en el modo del «ahí» (como una presencia). Está ahí en el modo del nacer" (Nancy, J.-L., Le Poids d'une pensée, Grenoble, Le Griffon d'Argile, 1991, pp. 133-134).

15 Nancy 2001b, op. cit. (nota 10), p. 53.

16 Ibidem, p. 26.
} 
Blanchot, y con la que ambos respondían a una "exigencia imposible": la de hacerse cargo de la muerte del otro como la única muerte que concierne a cada uno, como la única separación que puede abrirnos a la comunidad sin que nos esté permitido "hacer obra" de ella ("la conversación muda que, sosteniendo la mano "del otro que muere", "yo" prosigo con él, no la prosigo sencillamente para ayudarlo a morir, sino para compartir la soledad del acontecimiento que parece su posibilidad más propia y su posesión incompartible en la medida en que ella lo desposee radicalmente"17). Y, por lo demás, esa relación sexual, paradigma de la relación en general que depende de la heterogeneidad y de la heteronomía de los inconmensurables que entran en relación, ¿no es, precisa y muy exactamente, lo que tiene lugar ("¿y es que eso había tenido lugar?") en la segunda parte de La Communauté inavouable?

Y así fue como mi observación y mi hipótesis sobre esta "respuesta" a Blanchot desvió a Nancy de la respuesta a mi tesis para "sustituirla -de manera extraña-por una especie de tesis distinta [...]":

...pero, ya que me fuerzas a ello, desde luego trataré de decir esto, muy rápido: el texto de Blanchot concentra quizás todo su alcance en su cuestión final, «confiada a los otros» como él dice (en consecuencia, a nosotros), que es la pregunta acerca de la clase de palabras que hay que poder no decir, sino callar -callar lo que debe ser callado y que él ha llamado «lo inconfesable»-. Esto último, lo ha designado claramente -incluso si lo ha hecho a través de un laberinto singularmente oscuro- como la parte de lo heterogéneo, es decir, también de la mujer y de la diferencia consigo que sería la mujer (ella, que «desaparece» en el «final siempre incierto que está inscrito en el destino de la comunidad»). Fin de la comunidad, no relación como condición de la relación por perturbación del «grupo» (p. 70) homogéneo. Cómo decir no un indecible, sino esto: que esta perturbación mediante el amor «exclusivo, excesivo, terrorífico» (p. 70) no debe ser dicha, confesada, pues «no hay confesión que la revele» (p. 92).

Lo inconfesable es una violencia del amor en el corazón del vínculo social y que lo arruina $\mathrm{o}$, al menos, lo suspende. Esto es quizás una manera muy rápida de comprender, demasiado rápida, este texto de Blanchot.

Pero es necesario añadir que, respecto a la "clase de palabras" que podrían, que deberían sostener lo inconfesable, Blanchot habrá dado una triple indicación: en primer lugar, su propia palabra, aquí teórica, filosófica, no basta para la tarea, después, el texto literario de Duras, ¿sería suficiente? Ese texto es "irreductible", ha escrito Blanchot (p. 62 y 67), se nos hace saber que es irreductible o que escapa "también al autor". Pero si esta "escapada" final responde ella misma a lo "inconfesable", entonces, ¿por qué preguntar acerca de "la clase de palabras"? Entre las dos, otra palabra ha sido evocada: la del "esto es mi cuerpo". Se compara a la mujer, en efecto, con el "don absoluto, immemorial" (p. 91) del "cuerpo eucarístico" (que es preciso sin duda entender también en el sentido

17 Blanchot, M.; La Communauté inavouable, ed. cit., p. 21. En adelante citado CI en el texto. 
griego de la palabra...). La palabra de Cristo no se cita, sino que se evoca como si las palabras de la mujer la tradujesen. Y el Cristo/la mujer son ambos explícitamente vinculados a lo que hace que la "presencia divina" no sea reconocida -referencia a Emaús (pp. 91-92)- más que cuando ha partido.

Quizás podemos tratar de comprender que la palabra acerca de la cual se pregunta es aquella que deja oír una presencia que ha partido, retirada; única manera de hacerla oír. No es poco importante que de esta palabra se dé una referencia "divina". Habría que volver a ello mucho más ampliamente y, por supuesto, sin olvidar lo que todo esto disimula -o pronuncia en voz baja- ¡la palabra “comunión”!

Quizás podemos decir que si he respondido indirectamente a Blanchot ha sido desplazando el acento de la desaparición o de la muerte. Hay una desaparición como fin, sin vuelta atrás y en la noche (todo esto está en las páginas 91-92), pero hay también, hay más bien, en mi opinión, la desaparición como retirada [retrait] de la separación, la única mediante la cual es posible el "en-común" o el "con". Lo que yo querría hacer perceptible es que la "no-relación" - o el "entre", el espaciamiento, la différe/ance - no es nada negativo. Que la muerte está en el horizonte o, más bien, que ella está siempre ahí, inminente, como la separación que nos relaciona entre nosotros, los unos con los otros, sí, nada es más cierto; ya que sin la muerte estaríamos en un " común " que disolvería todas las singularidades. Eso no aligera el dolor de la pérdida (del otro, de sí): eso nos expone absolutamente aunque, exponiéndonos, nos dis-pone también entre nosotros.

Apenas es necesario recordar la génesis y el desarrollo de la red de textos Nancy-Duras-Blanchot ${ }^{18}$, pero cuando Blanchot publica en diciembre de 1983, La Communauté inavouable, el libro se presenta dividido en dos partes: "La comunidad negativa" y "La comunidad de los amantes". En la primera, y según sus propias palabras, se estaría haciendo cargo "de un importante texto de Jean-Luc Nancy”, La

18 "Desde la aparición de algunos fragmentos de la segunda [La Maladie de la mort] en Le Nouveau Commerce, [...] una nota final [de un comentario de Blanchot a La Maladie de la mort] remite a las páginas de Nancy "que deberían hacer época en el enfoque del pensamiento de George Bataille, todavía tan desconocido, a pesar o a causa de su fama". [...] Tejer los hilos de la necesidad, en un encuentro que podría no parecer más que azaroso, responde también a un movimiento secreto que prolonga y saca a la luz el trabajo que preparaba entonces Blanchot. Después de haber tenido conocimiento de una tesis sobre Bataille, que le había parecido que obviaba lo esencial sobre el pensamiento de la comunidad, Blanchot había retomado, en efecto, por su cuenta esta reflexión, de la cual una carta a Bruno Roy, aparecida en 1982 en un homenaje a Guy Lévis Mano, se hacía ya eco. La lectura de Nancy debió parecerle entonces como una coincidencia con mayor motivo feliz e impactante" (Bident, C., Maurice Blanchot. Partenaire invisible, Seyssel, Champ Vallon, 1998, p. 546). Este capítulo del libro de Bident lleva por título una cita de Nancy: «Avec cette cassure de l'historie dans la gorge» (Nancy, J.-L.; «Compagnie de Blanchot», Ralentir Travaux, 7 (hiver, 1997, p. 77). 
Communauté desœuvrée, y la segunda consistiría en "unas páginas escritas sin otro pensamiento que el de acompañar la lectura de un relato casi reciente" de Marguerite Duras, La Maladie de la mort. Como dice el propio Blanchot, las fechas no importan. Del mismo modo que poco importa tampoco esa estructura dual cuya disposición vamos a ver enseguida multiplicarse. El libro de Blanchot se presenta en efecto como un "díptico". Ahora bien, recordemos que, en su uso litúrgico en la Iglesia cristiana, la $\delta i \pi \tau v \chi \alpha$ es el libro formado por dos tablas plegables en el que se acostumbraba a anotar en dos listas pareadas los nombres de los vivos y de los muertos por quienes se debía rezar. Sin embargo, y más allá entonces, de la "respuesta" abierta a dos libros de dos amigos, Jean-Luc Nancy y Marguerite Duras, Blanchot multiplica infinitamente en su libro -el "tiers-livre"- los gestos de reconocimiento y, como explica Christophe Bident en Maurice Blanchot. Partenaire invisible, el entrecruzamiento de homenajes le sirve a Blanchot para seguir y perseguir una vez y otra las huellas de amistades pasadas y anunciar las amistades presentes 19 .

Sin embargo, la estructura del libro antes de ser la de la escritura lineal de dos partes contiguas, la una tocando a la otra en discordia o en armonía, en continuidad o ruptura, se presenta bajo la figura de un quiasmo en el que cada una de las partes queda sometida a la otra bajo la constricción de un vínculo, de una ligadura: el corazón del quiasmo. Bien sabemos, por lo demás, que ese corazón es un corazón vacío: la vacuidad sin vuelta atrás e irrevocable del desobramiento, único origen vacío de lo que hay y abierto a lo que viene 20 . Hay entonces entre las dos partes del libro una constricción, la ley sin ley de una obligación, "una obligación que precede a cualquier ley" (CI. p. 64), la imposición de hacerse cargo del desobramiento de esa relación sin relación que no nos autoriza a leer una parte de libro sin relación con la otra (e incluso menos como una relación de confrontación). Efectivamente, la "ley" de la relación -"responsabilidad u obligación [...] que no viene de la Ley, sino de donde ésta vendría en lo que la hace irreductible a cualquier forma de legalidad" (CI. p. 73) y que sólo encuentra su posibilidad si "puede afirmarse una relación anterior" a la ontología y a la ética-, la "ley" de la comunidad consiste en cierta "comunicación que no se comparte puesto que pasa por la supresión misma de la comunidad" (CI. p. 45 énfasis nuestro), "movimiento desesperado" para, en virtud

\footnotetext{
19 "El cruce de homenajes adquiere en consecuencia, en primer lugar, un sentido político: política del pensamiento, política de la amistad, pues permite retomar, mediante las dos figuras presentes (Nancy, Duras), pero también más allá de ellas, lo que supusieron ciertas respuestas esenciales en la ruptura contemporánea del espacio histórico: Contre-Attaque y el pensamiento de Bataille, Mayo del 68 y la presencia del pueblo (la parte sobre Duras, después de una introducción de algunas líneas, olvida enseguida La Maladie de la mort para abrirse de manera sorprendente hacia las marchas, los comités, evocando también a los muertos y a los manifestantes de Charonne)" (Bident 1998, op. cit. -nota 18-, pp. 546-547).

20 Nancy nos lo acaba de decir: el "entre" o el "vacío" sin el cual formaríamos parte de un "común" que disolvería todas las singularidades.
} 
de "la comunidad con lo imposible", "alcanzar la oportunidad de una comunicación más amplia" 21. Comunicación cuya base no es el habla, ni siquiera "el silencio que es su fondo y su puntuación" (sin que por lo demás Blanchot exprese aquí ningún misticismo), sino "la exposición a la muerte, no ya de mi mismo, sino del otro", siendo "en la vida misma" donde "esta ausencia del otro debe ser encontrada" y siendo con esta exposición a la muerte como "la amistad se pone en juego a cada instante y a cada instante se pierde, relación sin relación o sin otra relación que con lo inconmensurable" (CI. p. 46). La comunidad, por tanto, no está destinada a sanarnos de ninguna enfermedad de la muerte, sino que es la forma en que, precisamente, se nos expone a la muerte. No hay nada azaroso en ello, es la ley vacía de la comunidad. La ley de la relación es, por tanto, un corazón vacío; "el corazón o la ley", la misma cosa: la ley o el corazón con el que se "cierra" la primera parte del libro es el imposible engranaje, la misteriosa bisagra chirriante y perturbadora con que se "abre" la segunda: la ley del abandono y la del amor, la ley del abandono o la del amor, la ley del abandono como la del amor, la misma cosa: "última forma de la experiencia comunitaria" (CI. p. 46). El corazón vacío del quiasmo nos lleva así a pasar de una parte a otra del libro incesante e infinitamente como en una banda de Möebius sin que podamos estar seguros de si estamos en un lado o en el otro 22 : le cœur de la fraternité, el corazón vacío de "tout autre chose", de una "extrañeza" de lo que no podría ser común (CI. p. 89), está afirmado así por una misma palabra: "exigencia", la exigencia "comunista" (CI. p. 9) y la exigencia "comunitaria" (CI. p. 51), una exigencia que desencadena toda habla y que incita a una ineludible responsabilidad política y que, como dice Nancy, concentra todo su alcance en la pregunta final que Blanchot "nos confía" a todos acerca de la clase de palabras con las que hay que callarse para no callarse.

Agitación del habla en absoluto confusa; y cuando se calla, no se calla: yo podía distinguirme en ella, oírla solamente oyéndome en ella, inmenso decir que dice siempre "Nosotros". La clase de embriaguez que brota del habla venía de ese "Nosotros" que brota de mí. ${ }^{23}$

Exigencia, atestiguada por "la comunidad literaria", que "resuena para todos y para cada uno", comprendidos ahí, "los que no escriben ni leen, y los que no tienen

\footnotetext{
21 "Comunicación más amplia" siempre susceptible de mancillarse por "el énfasis dicho y vivido por uno solo en quien todos «se encarnan»" (CI. pp. 45-46).

22 Un ejemplo significativo de esa transferencia entre las dos partes del libro es, precisamente, la figura femenina, representada por Madame Edwarda, que atraviesa incesantemente las dos partes del texto. Ella expone para todos y para nadie, para "el primero que llega", esta ley del abandono. Véase «Sacrifice et abandon», «Le partage du secret», «Etique et amour» y «Communauté traditionnelle, communauté élective».

23 Blanchot, M., Le Dernier homme, París, Gallimard, 1957, pp. 111-112.
} 
nada en común" 24 , exigencia que nos hace "responsables de relaciones nuevas" y que está consagrada a evitar cualquier modelo inmanentista y totalitario (así como cualquier modelo de trascendencia, salvo quizás aquel que puede "dar a la vida una trascendencia sin gloria").

Se trata pues de "relación", de la relación entre lo que "hay", en cuanto presente y disponible, y lo que "tiene lugar", en cuanto aparición de la sorpresa, siempre amenazante y siempre "amenazada" y siempre "esperada", se trata de la relación "entre lo que llamamos obra y lo que llamamos desobramiento". Toda la inquietud que nos transmite Blanchot en su texto viene dada por la "exigencia" de ese saber de la relación que, precisamente, ya no es objeto de un saber, sino que "sobrepasa el entendimiento", abocándole a "responder de ello por entero sin que tenga el poder de hacerlo" (CI. p. 59). Y, sin embargo, ese no-saber es lo que, con respecto al libro de Duras, le "autoriza a retomar como si fuera nueva la lectura y su comentario". De ahí las distintas "lecturas" propuestas por el propio Blanchot en estas densísimas cuarenta páginas y que no son sino un tanteo, una búsqueda exploratoria sin resolución, sin desenlace. Si el texto es "enigmático", "opaco, misterioso en el sentido de la palabra de no esclarecedor", "irreductible" porque "escapa también al autor", "enigma que se oscurece tanto más cuando pretendemos ponerlo al descubierto" (CI. p. 65), tal vez no lo sea sino en virtud de su evidencia, misterioso precisamente por evidente, "evidencia -la realidad última- [que] nunca está mejor afirmada que en la inminencia de su desaparición" (CI. p. 88). Evidencia que ya no tiene ninguna necesidad de demostrarse o esclarecerse puesto que "tiene lugar" y, teniendo lugar, en la inminencia de la desaparición, se muestra evidente. ¿Cuál podría ser esa evidencia? Acaso aquello que es al mismo tiempo nuestra grandeza y nuestra condena: que sólo podemos reconocer nuestra comunidad (sin que podamos "reconocer" nada ahí) en el instante preciso de perderla y eso, precisamente, es lo inconfesable. Finalmente, entonces, no queda sino la evidencia: intentar argumentar o teorizar arruinaría una evidencia que se transformaría en objeto de reflexión. Sólo queda entonces una exigencia que nos impone "ir más lejos en la búsqueda (y no en la elucidación)", "sin que nos esté permitido detenernos ahí".

Aunque, según Blanchot, "hay seguramente un abismo entre la potencia impotente del $[\ldots]$ pueblo [...] y la extrañeza de esta sociedad antisocial o de la asociación siempre dispuesta a disociarse que forman los amigos y las parejas" (potencia impotente y extrañeza llamando una y otra "al abismo, a la noche negra que descubre el vacío vertiginoso de las piernas separadas"), hay también ciertos rasgos "que los aproximan" (CI. p. 57). Paradójicamente, esos rasgos o más bien el rasgo que los aproxima es, precisamente, la imposibilidad de su relación, su amor imposible.

En la relación sexual, como ya hemos tenido ocasión de ver, lo que se pone "en evidencia" es la inconmensurabilidad absoluta de la relación, "relación con lo más

24 Nancy 1986, op. cit. (nota 12), p. 104. 
divino que hay o con lo absoluto que rechaza cualquier asimilación" (CI. p. 80), porque no hay resultados, ni informes, ni cuentas rendidas ni razones dadas de la relación sexual. Lo que está en juego entre los amantes es "la tentativa de amar", efectivamente, pero "para Nada, tentativa que no tiene finalmente ningún otro objeto que la nada que los anima sin que ellos lo sepan y que no los expone a nada más que a tocarse vanamente" (CI. p. 82), para poder escapar así de lo que los convertiría en "un conjunto aprehensible, una suma que integraría el infinito y así lo reduciría en un finito integrable" (CI. p. 66). Sin embargo, la "finitud" de la relación debe ser comprendida como lo que "puntualiza" la "infinitud" en la relación sexual: "Es el buen infinito o el infinito actual; es la infinidad en acto del acto mismo en cuanto es el acto de excederse. El sexo se excede por esencia y, por eso, de nuevo se excita"25. Se (ex)cita. Se cita. Se llama. Se profiere, mana o brota fuera. Sólo una apelación, una llamada, un sex-appeal, como dice Nancy. Una llamada que no espera ser respondida sino relanzada, vuelta a poner en juego, repetida, repercutida. Es por eso que el deseo no se extingue al apaciguarse. Se excede otra vez. Llamada relanzada y reactivada por el otro para que la relación tenga lugar (y no sólo para que la haya) con sus idas y venidas. La relación sexual se revela como lo que abre un orden distinto tanto de las cosas como de las significaciones: "un orden del sentido -y de los sentidos del sentido- donde entran en juego unos signos que no producen significación alguna pero sí placer-deseo"26. Una llamada o una apelación que puede tener lugar entre dos miradas, dos entonaciones o dos gestos: "envío de una enunciación sin enunciado"27. A esa llamada, a esa palabra excesiva "más allá del silencio" con que la palabra se dirige "a lo que la excede soberanamente" 28 , Nancy le ha dado recientemente un nombre: "adoración”. Pero, ¿con qué clase de palabras? Quizás tenemos ya una respuesta a esta pregunta: con palabras de adoración, "adoración, un hablar dirigido a lo que el habla sabe sin acceso"29.

En la relación sexual no se hace sino intercambiar algunas señales de llamada. En ella la relación se expone y plantea así su carácter "irreferible", "irraportable",

25 Nancy 2001b, op. cit. (nota 10), p. 39.

$26 \mathrm{Si}$ bien no produce significados ese placer-deseo produce figuras infigurables del infinito en acto: "Las figuras claramente rivales - lo cual no quiere decir contrarias- del amor y del deseo se denominan la fidelidad y el flechazo fulminante. En más de un aspecto, cada una excluye la otra. La fidelidad no consiste en mantener un fuego cuya esencia es consumirse: por esa razón, no hay transición entre una y otra y una puede destruir a la otra de manera que, aunque coexistan, no por eso dejan de ser menos heterogéneas entre sí. Sin embargo, el flechazo y la fidelidad son asimismo dos figuras del infinito en acto, es decir, de lo que se denomina la eternidad: una figura de acuerdo con la consunción, otra de acuerdo con la asunción. Una eternidad presente en el instante, una eternidad en cuanto fe prometida más allá de todos los instantes. Ahora bien, tal vez no haya eternidad sin la relación íntima y dividida de ambas: el eterno retorno es la afirmación de un presente más allá de toda presencia". Ibidem, p. 50.

27 Ibidem, p. 47.

28 Nancy, J.-L., L'Adoration (Déconstruction du christianisme, 2), París, Galilée, 2010, p. 100.

29 Ibidem, p. 11. 
el carácter que la coloca fuera de la relación y fuera del habla. Eso es "inconfesable", por supuesto, sí. No se dice ni se escribe la "relación" consignada, reportada, registrada. No se dice ni se escribe la relación sexual. Acaso sólo se profiere, es decir, se lleva hacia fuera, "se la prolonga". Pero ahí donde no hay nada que decir ni que reportar, la relación sexual sólo hace lo que dice y dice lo que hace: la relación misma. Tautología que conduce el lenguaje al límite de la significación: "El habla viene aquí a mostrar lo que no se muestra, o bien viene a subrayar que hay un exceso sobre lo mostrable; como un paradójico exceso de sentido sobre la sensualidad misma y como un suplemento de confesión de lo inconfesable"30. Se dice con un hacer, se hace con un decir que, precisamente, lo único que dice es "sí" y repite el "sí" de su acto. Inconfesable "sí" que sólo se calla para no callarse, para volver a empezar y decir de nuevo "si'".

Afirmación, en consecuencia, afirmación de una relación singular entre los seres, exposición de singularidades que sólo se unen para "vivir (y de cierta manera, celebrar) el fracaso que sería su unión perfecta" (CI. p. 82), comparición de finitudes cuya finitud desaparece en el instante mismo de su comparecencia. La desaparición, o la muerte, es el vínculo invisible y fugaz de la comunidad; y la relación sexual consiste en la cuvre de chair, carne contra carne, cuerpo contra cuerpo, que tiene como único "resultado" el imposible resultado, el desœuvrement de una muerte que los amantes se revelan y se dan el uno al otro a través de sus ojos 31 .

Afirmación de una relación tan singular entre los seres que el amor mismo no es necesario en ella, puesto que éste, que por otra parte no está nunca seguro, puede imponer su exigencia en un círculo en donde su obsesión llega a tomar la forma de la imposibilidad de amar: o sea, el tormento no sentido, incierto, de los que habiendo perdido "la inteligencia del amor" (Dante) quieren sin embargo tender aún hacia los únicos seres a los que no podrían acercarse por medio de ninguna pasión viviente. (CI p. 58)

Blanchot ya nos había dicho con anterioridad quiénes son esos seres a los que a los hombres les es imposible acercarse mediante alguna pasión viviente: "Donne" que tienen "intelletto d'amore", "hermosas criaturas", cómplices de la muerte al ser secuaces de la vida, y que Blanchot había encontrado ya en La folie du jour. Para acercarse a esos seres, los hombres deberían conocer una pasión premoriente. Esos

\footnotetext{
30 Nancy, J.-L.; «Exclamations», en Di Folco, Ph. (Ed.), Dictionnaire de la pornographie, París, PUF, 2005, p. 169 .

31 Jean-Luc Nancy me ha hecho observar de manera muy pertinente que la muerte que los amantes se dan, se la dan también con sus palabras, si las dicen, o con su silencio, así como con todo el cuerpo; por ese motivo estamos más allá de la mirada. Por supuesto, nada que objetar, pero sería preciso desplegar toda la problemática de una disimetría absoluta que se pone en marcha, precisamente, mediante el cruce de miradas y de unos ojos que no son sólo videntes, sino visibles. Tenemos ante los ojos una importante cuestión para implicarnos y trabajar en ella.
} 
seres "que jamás le han dicho a la vida, cállate, y nunca a la muerte, vete" 32 . Hacia ellas quisieran tender los hombres, "rara especie", que siempre "querrían escapar a la muerte" y que, sin embargo, piden "morir, morir, porque querrían escapar de la vida". Rara especie afectada entonces por la enfermedad de la muerte y que ignora que esa enfermedad es mortal precisamente porque el que está afectado por ella no se sabe su portador, "muerto sin vida previa a la que morir, sin conocimiento alguno de morir a alguna vida"33. Pero, durante el tiempo que están juntos, ambos son premorientes y cada uno se vuelve así singularmente exclusivo para el otro (muero antes que tú, en tu lugar, me hago cargo de tu muerte). Se dan y se manifiestan su exclusividad, exponiéndose el uno al otro y así se dotan de un precio exclusivo, absoluto e inconmensurable (noches pagadas, pero sin precio establecido; aunque será caro $^{34}$ ). Para aquello para lo que hay que acordar un precio elevado, para lo que es caro (carus), el latín empleaba la palabra caritas. La caritas cristiana afirma el precio exclusivo que debe ser el precio de cada uno. En ese sentido, afirma Nancy, que no puede haber relación más que "si cada uno de sus términos ("sujetos") puede ser dotado de un valor singular exclusivo"35.

Que [...] sólo el eros inervando el ágape [carus, caro, es la trascripción latina del griego ágape] pueda volver manifiesta esta exclusividad, y que ésta no se produzca más que de manera exclusiva, entre tal y tal, es una cosa, pero que sea exigible para todos, no puede ofrecer ninguna duda. Los amantes están fuera del mundo: pero de manera ostensible o no, están encargados de ese "afuera" para todo el mundo. Sin eso hay que renunciar a pensar el hombre y el mundo. ${ }^{36}$

Es así como el amor declara lo imposible mismo, es así como el amor se empeña en un gesto exorbitante tanto para el que lo da como para el que lo recibe. Este amor imposible que se extiende desde la pasión erótica hasta el fervor espiritual es debido exclusivamente a lo siguiente: "la relación se deja arrastrar en él hacia la incandescencia al dirigirse a lo que, en el otro, le es inconmensurable a partir de lo que lo es también en mí" 37 . Dirigiéndose a lo que, en el uno y en el otro, es inconmensurable, la relación que mantienen arrastra también hacia la incandescencia ${ }^{38}$ la evidencia de esa muerte que se dan uno al otro para responder con ella a la "exigencia imposible" de exponerse, uno en el lugar del otro, "a la dispersión de la muer-

\footnotetext{
32 Blanchot, M., La Folie du jour, Montpellier, Fata Morgana, 1973, rééd. Gallimard, 2002, p. 13.

33 Duras, M., La Maladie de la mort, París, Minuit, 1982, p. 24.

34 Ibidem, p. 8.

35 Nancy 2010, op. cit. (nota 28), p. 87.

36 Ibidem, p. 87.

37 Ibidem, p. 88.

38 "El beso, por la noche, / imprime la combustión del sentido en una lengua" (Celan es citado por Nancy 2001b, op. cit. -nota 10 -, p. 40.)
} 
te". Evidencia de "dos seres que no tienen más razones para existir que exponerse enteramente uno a otro, enteramente, íntegramente, absolutamente, con el fin de que comparezca, no ante sus ojos, sino ante los nuestros su común soledad" $(C I$, p. 83).

La literatura y la relación sexual, la obra literaria y la obra de carne ${ }^{39}$ (ambas exponentes de esa "comunicación nocturna, la que no se confiesa") no reúnen (ni funden, ni fusionan), sino que exponen y dejan que comparezca lo inconfesable: la muerte. Una muerte que, como escribe Nancy, no tiene nada de negativo, sólo por ella es posible el "con". La literatura y el sexo (comunidad literaria, comunidad sexual) aparecen entonces como el doble paradigma de la relación en general, una relación de "adresse" y de "appel" a través de la cual, no sólo un yo se dirige a un tú, sino que por ella puede haber algo como un yo y un tú y, únicamente por ella, puede ocurrirnos "tener ojos sólo para el otro [...], pero como el único que eclipsa a todos los demás y los anula", de ahí que "la desmesura sea su única medida y que la violencia y la muerte nocturna no puedan ser excluidas de la exigencia de amar" (CI. p. 76). "Comunidad de la escritura" y/o "comunidad de los amantes" deben responder a la "exigencia imposible" de exponerse "a la dispersión de la muerte" y hacerlo, además, a través de sus obras, cuando la obra "es de antemano renuncia a hacer obra, indicando solamente el espacio en que resuena, para todos y para cada uno, por tanto, para nadie, el habla siempre por venir del desobramiento" (CI. p. 77).

Finalmente, para acabar, y como una forma de mantenerme fiel a un pacto al que espero no faltar jamás y, así, puesto que no he podido imponerme silencio a mi misma, quisiera cargar con la cuestión y prolongarla. Y para cumplir con la parte que me toca, quiero dejar aquí planteadas algunas cuestiones. Nancy ha escrito que, quizás, la palabra evocada por Blanchot es la de la vieja fórmula eucarística del "hoc est enim corpus meum". Ciertamente, la mujer es comparada por Blanchot con el cuerpo eucarístico y la presencia divina retirada ("recuerdo del amor perdido, antes de que éste haya podido advenir") es evocada a través de lo ocurrido en la aldea de Emaús. Pero esa (es)cena es una (es)cena de más (como diría Derrida "siempre hay que contar con uno de más a cenar en la (es)cena de la lengua"40), esa cena no es la Última Cena, es una cena después de la última, no es la cena del "tomad y comed todos de él: esto es mi cuerpo", no es la escena de la memoria y de la conmemoración, sino una escena repetida, como doblada, en la que todo ocurre como si debiera confirmarse por su duplicación. De hecho, Cristo sólo es reconocido en el momento del reparto del pan porque, precisamente, ya lo había hecho antes; no es por tanto su persona, no es a Él a quien los discípulos de Emaús reconocen, sino el hecho mismo del reparto, el acto de la partición. Pues, cuando Jesús

39 Esta ouvre de chair aludiría en francés (por hacer un guiño al léxico blanchotiano en su marcada ascendencia católica) a la relación sexual tal y como la pone en circulación el noveno de los Mandamientos de la Ley de Dios: "L'œuvre de chair ne désireras qu'en mariage seulement".

40 Derrida, J., Glas, París, Galilée, 1974, p. 14. 
aparece en la aldea de Emaús, los discípulos no lo vieron, no podían verlo, "sus ojos estaban como imposibilitados para reconocerlo" 41 . No se trata entonces de una escena que haya que ver con los ojos, sino de una experiencia en el corazón 42 (“¿verdad que dentro de nosotros ardía nuestro corazón cuando nos venía hablando por el camino?"43). Una escena que se hurta a los ojos para implicarse en una extraña relación con aquello que precisamente ya no es susceptible ni de olvido ni de memoria, "pues jamás lo hemos vivido ni conocido" y sin embargo "no nos abandona": lo inmemorial.

Lo inmemorial es por excelencia lo que precede al nacimiento: lo ausente de todo recuerdo hacia lo que remonta sin fin una memoria infinita, hipermemoria o más bien inmemoria. Más acá o más allá del memorial, es decir, más acá o más allá del sí y de lo subjetivable: el otro-mundo (la muerte, en ese sentido), no fuera del mundo, sino presente aquí mismo. 44

¿No estaremos ante una poderosa confirmación de que el pan en esta (es)cena conservaría lo inmemorial de toda deconstrucción? ¿No estaremos ante una singular constatación de la deconstrucción del cristianismo? ¿Y la vieja fórmula eucarística no podría aparecer como la palabra misma portadora de la dirección de la palabra y de la apelación que abre cualquier palabra o pensamiento? Por tanto, no ya hoc est corpus meum, sino un cuerpo no mío, non hoc corpus quod videtis, no éste cuerpo que veis, sino un cuerpo perdido, entregado, hoc corpus quod pro vobis tradetur, abandonado, el cuerpo abandonado que obsesionó también a Blanchot, ese cuerpo perdido que es la pasión de la escritura ("la escritura no puede más que perderlo. En cuanto lo toca, ella pierde su tacto. En cuanto lo traza, lo borra"45).

Nada menos, de hecho, que la apuesta del cristianismo en cuanto que él mismo se deconstruye, es decir, en cuanto que se deshace de la religión, de su leyenda y de su creencia, para convertirse en la agitación de una inmemoria de la presencia: los dioses retirados han retirado con ellos la presencia misma. La verdad del monoteísmo es el ateísmo de esa retirada. La "presencia real" se transforma en la presencia que por excelencia no está presente: la que no está ahí. [...] Esto es mi cuerpo. Esto es la exposición de la piel o del velo bajo los cuales ninguna presencia se oculta y ningún dios espera, sino el lugar mismo, aquí, y el toque singular de nuestra propia exposición: gozo y sufrimiento de estar en el mundo, exactamente aquí y en ninguna otra parte. 46

\footnotetext{
41 (Lucas, $24: 16$ ).

42 Véase Nancy, J.-L., «Une expérience au cœur», en La Déclosion (Déconstruction du christianisme, 1), París, Galilée, 2005.

43 (Lucas, $24: 32$ ).

44 Nancy, J.-L., Visitation (de la peinture chrétienne), París, Galilée, 2001, p. 10.

45 Nancy, J.-L., Une Pensée finie, París, Galilée, 1991, p. 294.

46 Nancy 2001c, op. cit. (nota 44), pp. 45-46.
} 